\title{
Open access: does it address our problems? SM Bachrach
}

Address: San Antonio, TX, USA

from 4th German Conference on Chemoinformatics

Goslar, Germany. 9-II November 2008

Published: 5 June 2009

Chemistry Central Journal 2009, 3(Suppl I):OI5 doi:I0.II86/I752-I53X-3-SI-OI5

This abstract is available from: http://www.journal.chemistrycentral.com/content/3/SI/OI5

(c) 2009 Bachrach; licensee BioMed Central Ltd.

Chemistry publishing suffers from multiple problems: journals that are very expensive, an explosion in the number of publications (both in terms of actual papers and the number of journals), library budget increases that fail to meet inflation rates. The net result is that chemists face an increasing inability to access the complete literature. Proponents of Open Access (OA) hope to address this problem by removing the costs of access to the literature. In my talk, I address how OA may not prove suitable to address the cost issues. Furthermore, I argue that OA does not address the more critical issues of information overload and lack of progress in the technology of chemical publishing. Chemists need to focus on what should and should not be published and the technologies to do so in an enhanced manner. 